Research Paper

\title{
Clinicopathological Implications of the Expression of Hypoxia-related Proteins in Gastric Cancer
}

\author{
Ji-Han Jung ${ }^{1}$, Soyoung $\operatorname{Im}^{1 \bowtie}$, Eun Sun Jung ${ }^{2 \bowtie}$, Chang Suk Kang ${ }^{3}$ \\ 1. Department of Hospital Pathology, St. Vincent's Hospital, College of Medicine, The Catholic University of Korea, Republic of Korea \\ 2. Department of Pathology, Seoul St. Mary's Hospital, College of Medicine, The Catholic University of Korea, Republic of Korea \\ 3. Department of Hospital Pathology, Yeouido St. Mary's Hospital, College of Medicine, The Catholic University of Korea, Republic of \\ Korea
}

\begin{abstract}
$\triangle$ Corresponding author: Soyoung Im, M.D ${ }^{1}$. and Eun Sun Jung, M.D. Ph.D². Department of Hospital Pathology, St. Vincent's Hospital, The Catholic University of Korea, 93, Ji-dong, Paldal-gu, Suwon 442-723, Republic of Korea. Tel: 82-31-249-7633, Fax: 82-31-244-6786, E-mail: st9747@catholic.ac.kr ${ }^{1}$, Department of Pathology, Seoul St. Mary's Hospital, The Catholic University of Korea, 505 Banpo-dong, Seocho-Gu, Seoul 133-782, Republic of Korea, Tel: 82-2-2258-1619, Fax: 82-2-2258-1628, E-mail: esjung@catholic.ac.kr²
\end{abstract}

(c) Ivyspring International Publisher. This is an open-access article distributed under the terms of the Creative Commons License (http://creativecommons.org/ licenses/by-nc-nd/3.0/). Reproduction is permitted for personal, noncommercial use, provided that the article is in whole, unmodified, and properly cited.

Received: 2013.02.09; Accepted: 2013.07.22; Published: 2013.07.31

\begin{abstract}
Objectives: Tumor hypoxia confers poor prognosis of a wide range of solid tumors due to increased malignancy, increased likelihood of metastasis and treatment resistance. The aim of this study was to assess the significance of the expression of HIF-I $\alpha$ and HIF-I $\alpha$-inducible proteins in gastric cancer and their impact on prognosis. Materials and Methods: The expression of HIF-Ia, GLUT-I, CA-9, and iNOS proteins was analyzed by immunohistochemistry in 193 gastric adenocarcinomas (GAs) and 20 normal gastric mucosa. Results: HIF-I $\alpha$, GLUT-I, CA-9 and iNOS were expressed in $52.3 \%, 43.0 \%, 57.0 \%$, and $43.0 \%$ of GAs, respectively, which are higher than the normal counterparts except for CA-9. HIF-I $\alpha$ expression was positively correlated with the expression of GLUT-I, CA-9 and iNOS. GLUT-I expression was higher in the intestinal type $(p=$ 0.012 ); however, iNOS expression was higher in the less-differentiated type and the diffuse type ( $p$ $=0.006, p=0.032$, respectively). The expression of HIF-I $\alpha$ and GLUT-I was significantly correlated with lymph node metastasis $(p=0.009, p=0.008$, respectively), while the expression of GLUT-I and iNOS was significantly correlated with the depth of invasion and advanced stage $(p=$ $0.044, p=0.004 ; p=0.009, p=0.008$, respectively). Overall survival was shorter in patients with GLUT-I expression than in those without GLUT-I expression, which was statistically significant by univariate analysis $(p=0.042)$. On multivariate analysis, however, stage was determined as the only independent prognostic marker $(p<0.00 \mathrm{I})$. Conclusions: Our data suggest that overexpression of HIF-I $\alpha$, GLUT-I, and iNOS may play an important role in gastric cancer progression. GLUT-I is a potential candidate for predicting patient survival.
\end{abstract}

Key words: Gastric cancer, hypoxia, HIF-1a, GLUT-1, CA-9, iNOS

\section{Introduction}

Gastric cancer is the fourth most common cancer and is the second leading cause of cancer-related death worldwide [1]. In spite of advances in chemotherapy, no clear standard chemotherapy regimen has been established, and the only curative treatment for gastric cancer is surgical resection of primary tumors with appropriate lymphadenectomy [2]. Therefore, due to limited treatment options and poor prognosis, gastric cancer still remains a major clinical challenge. Improvements in the treatment of the disease must arise from a better understanding of the underlying molecular mechanisms explaining progression, invasion and metastasis formation.

Hypoxia is now recognized as a key factor 
driving the development of malignancy and promoting tumor metastasis [3]. The key transcriptional regulator for vells in response to changing oxygen levels is hypoxia-inducible factor-1a (HIF-1a). Under the condition of normoxia, HIF-1a is continuously degraded by proteasomes via the ubiquitin pathway [4]. However, in the hypoxic environment, the HIF-1a degradation pathway is inhibited and HIF-1a is stabilized. The stabilized HIF-1 $\alpha$ is then dimerized with HIF-1 $\beta$, and forms the transcriptionally active HIF-1 complex [3]. Subsequently, it acts as a master regulator of numerous hypoxia-inducible genes that are related to tumor angiogenesis, cell proliferation or survival and glucose metabolism [5]. HIF-1a-inducible proteins which may be important in cancer include glucose transporter 1 (GLUT-1), carbonic anhydrase 9 (CA-9), erythropoietin (Epo), inducible nitric oxide synthase (iNOS), and vascular endothelial growth factor (VEGF) [5]. Thus, increased expression of hypoxia-related genes could be associated with malignant potential and unfavorable patient prognosis. Most studies have detected overexpressed hypoxia-related genes including HIF-1a in cancer and have shown their correlations with highly aggressive phenotypes and poor prognosis [6-10]. However, only few studies have investigated the correlation between hypoxia-related genes and gastric cancer [11-16].

The aim of the present study was to examine the expression of HIF-1a and HIF-1a-inducible proteins (GLUT-1, CA-9, and iNOS) in human gastric adenocarcinomas (GAs). Next, we evaluated the association between the expression of these proteins and their clinicopathological characteristics and assessed their clinical significance. There has recently been interest in hypoxia-related genes as a target for cancer therapy $[17,18]$. Therefore, blocking HIF-1a or GLUT-1 activity has the potential to inhibit cancer progression by depriving cancer cells of the means to adapt to hypoxia and the nutrient depleted environment. From this point of view, this study regarding the expression of hypoxia-related proteins in gastric cancer may hold the key to a greater individualization of therapy and new treatment measures for patients with gastric cancer.

\section{Materials and Methods}

\section{Study material}

A total of 193 cases of primary GAs were acquired from the Catholic University Hospital, Seoul, Korea from January 2009 to May 2010. Additional 20 cases of normal gastric mucosa were included. The study protocol was approved by the Institutional Review Board of at The Catholic University of Korea. All patients had undergone complete tumor resection.
None of the patients had received preoperative chemotherapy or radiation therapy. The histologic types of tumors were re-classified according to the revised World Health Organization (WHO) classification. Tumors were then divided into two histological subgroups: a differentiated type consisting of papillary adenocarcinoma and well to moderately differentiated tubular adenocarcinomas, and a less-differentiated type consisting of poorly differentiated tubular adenocarcinomas, poorly cohesive carcinomas including signet ring cell carcinomas, and mucinous adenocarcinomas. All patients' stages were re-evaluated in accordance with the guidelines of the $7^{\text {th }}$ edition of American Joint Committee on Cancer Staging system. After surgery, clinical follow-up data were obtained from all patients. Survival time was measured as the time from the date of initial surgery to the date of death. Patients that died as a result of surgery or from other causes were excluded from the study.

\section{Construction of the tissue microarray (TMA) block}

Formalin-fixed paraffin-embedded tissues were obtained from subjects. Using H\&E-stained slides, a representative tumor site was chosen and the site corresponding to the confirmed tumor site in the paraffin block was marked. Areas with necrosis, hemorrhage, and artifacts were excluded. Single core biopsy specimens of $2 \mathrm{~mm}$ in diameter were taken from the representative regions (SeongKohn Trader's Co, Seoul, Korea), placed on a TMA mold with 60 pores, and re-embedded with paraffin. TMA blocks were prepared as 4 - $\mu \mathrm{m}$-thick sections and were stained with the H\&E staining methods. The tissues were then examined to determine whether the appropriate tumor site had been selected.

\section{Immunohistochemistry}

Immunohistochemical stainings were conducted on $5 \mu \mathrm{m}$ sections of the tissue microarray blocks by the manual procedure. The paraffin sections were mounted on superfrost glass slides, deparaffinized, and rehydrated in a graded series of ethanol, followed by microwave antigen retrieval. Endogeneous peroxidase activity was blocked using $0.3 \%$ hydrogen peroxide. The sections were incubated for 1 hour or overnight at $4^{\circ} \mathrm{C}$ using the following primary antibodies at a dilution of 1:100 against HIF-1a (Novus, Littleton, CO, USA), at 1:200 against GLUT-1 (Cell Marque, CA, USA), and at 1:500 against CA-9 (Novus, Littleton, CO, USA) and iNOS (Santa Cruz Biotechnology, Santa Cruz, CA, USA). Immunostaining was conducted using the rabbit or mouse DAKO ChemMate $^{\mathrm{TM}}$ EnVision $^{\mathrm{TM}}$ system, Peroxidase/DAB kit 
(DAKO, Glostrup, Denmark). The sections were then counterstained with Meyer hematoxylin and were then dehydrated, cleared, and mounted. Renal medulla was used as a positive control for HIF-1a and CA-9. Colon cancer was used as a positive control for GLUT-1 and iNOS.

All immunostained slides were evaluated independently by two independent pathologists. The evaluation was done twice without the evaluator having any knowledge of the specific diagnosis and prognosis of each individual case. Nuclear staining for HIF-1a, membranous staining for GLUT-1 and CA-9, and cytoplasmic staining for iNOS were considered in the evaluation. Cells were scored broadly, according to the staining intensity and the percentage of positive tumor cells. Staining intensities were scored as follows: absence of stain, 0 point; weak staining intensity, 1 point; moderate to strong staining, 2 points. The distribution of stained cells (dependent upon the percentage of stained tumor cells) was scored as follows: no staining or less than $10 \%, 0$ point; between 10 and $50 \%, 1$ point; more than $50 \%, 2$ points. The final staining score was obtained by adding the scores of staining intensity and distribution score of stained cells. Scores from 0 to 1 were considered negative and scores ranging from 2 to 4 were considered positive. Immunohistochemical staining was re-evaluated for cases showing disagreement between pathologists. Two pathologists reviewed those cases together, and reached an agreement for samples with inconclusive results.

\section{Statistical analysis}

Associations between categorical variables were analyzed using the SPSS software package, version 13.0 (SPSS Inc., Chicago, IL USA). Two-sided P values were determined via Chi-square tests. Patient overall survival was analyzed using the Kaplan-Meier method with the use of the log-rank test for univariate analysis. The Cox proportional hazards model was used in the multivariate analysis of the factors that were determined to be significant for overall survival by univariate analysis. For all analyses, the level of significance was set at $p<0.05$.

\section{Results}

\section{Patient characteristics}

Among the 193 patients studied, 123 (62.2\%) were men and $70(36.3 \%)$ were women, with a mean age of 63 years (range, 27 to 86 years). The clinicopathological data of our study population are presented in Table 1. Follow-up data were available in 193 patients, and the median follow-up duration was 32.9 months (range, 1.6-43.0 months) after primary surgery. Twenty-eight patients died during the follow-up period, and 165 patients remained alive at the time of the study.

Table I. Clinicopathological characteristics of 193 patients

\begin{tabular}{|c|c|}
\hline characteristics & Number of cases \\
\hline \multicolumn{2}{|l|}{ Age (years) } \\
\hline$<60$ & 118 \\
\hline$\geq 60$ & 75 \\
\hline \multicolumn{2}{|l|}{ Gender } \\
\hline male & 123 \\
\hline female & 70 \\
\hline \multicolumn{2}{|l|}{ Histologic type } \\
\hline differentiated & 108 \\
\hline less-differentiated & 85 \\
\hline \multicolumn{2}{|l|}{ Lauren classification } \\
\hline intestinal & 130 \\
\hline diffuse & 63 \\
\hline \multicolumn{2}{|l|}{ T classification ${ }^{\mathrm{a}}$} \\
\hline $\mathrm{T} 1$ & 80 \\
\hline $\mathrm{T} 2$ & 26 \\
\hline $\mathrm{T} 3$ & 33 \\
\hline $\mathrm{T} 4$ & 54 \\
\hline \multicolumn{2}{|l|}{$\mathbf{N}$ classification ${ }^{b}$} \\
\hline No & 107 \\
\hline N1 & 26 \\
\hline N2 & 24 \\
\hline N3 & 36 \\
\hline \multicolumn{2}{|l|}{ M classificationc } \\
\hline M0 & 193 \\
\hline M1 & 0 \\
\hline \multicolumn{2}{|l|}{ Stage } \\
\hline I & 91 \\
\hline II & 42 \\
\hline III & 60 \\
\hline \multicolumn{2}{|l|}{ M, male; F, female } \\
\hline \multicolumn{2}{|c|}{$\begin{array}{l}\text { TNM classification, aT was classified according to depth of invasion as follows: } \mathrm{T} 1 \text {, } \\
\text { invasion to lamina propria or submucosa; } \mathrm{T} 2 \text {, invasion to muscularis propria ; } \mathrm{T} 3 \text {, } \\
\text { invasion to subserosa; T4, penetration to serosa or invasion to adjacent structure }\end{array}$} \\
\hline \multicolumn{2}{|c|}{$\begin{array}{l}\text { }{ }^{\mathrm{N}} \text { was classified according to the number of involved regional lymph nodes as } \\
\text { follows: N0, no lymph node spread; N1, } 1 \text { to } 2 \text { diseased lymph node spread; N2, } 3 \\
\text { to } 6 \text { diseased lymph node; N3, more than } 7\end{array}$} \\
\hline $\begin{array}{l}\text { cM was classified accord } \\
\text { distant metastasis }\end{array}$ & as follows: M0, no distant metastasis; M1, \\
\hline
\end{tabular}

\section{Expression of HIF-I $\alpha$, GLUT-I, CA-9 and iN- OS}

The microscopic features of immunohistochemical staining for each protein are presented in Fig. 1. In normal gastric mucosa, HIF-1a, GLUT-1, and iNOS were not expressed. On the other hand, a distinctive pattern of strong membranous staining of CA-9 was observed at the level of foveloar epithelium and oxyntic glands in 20 cases of normal gastric mucosa. Out of the 193 gastric adenocarcinoma (GA) cases, HIF-1a GLUT-1, CA-9 and iNOS were expressed in $101(52.3 \%), 83(43.0 \%), 110(57.0 \%)$, and $83(43.0 \%)$ cases, respectively. In GAs cells, HIF-1a was localized in the nuclei of cancer cells. Concomitant cytoplasmic staining was not counted because HIF-1a in the nu- 
cleus determines the functional activity of the HIF-1a complex [4]. GLUT-1 and CA-9 were shown to have a strong membranous pattern of cancer cells. Conversely, iNOS was expressed in the cytoplasm of cancer cells.

\section{Relationship between HIF-I a, GLUT-I, CA-9, and iNOS and clinicopathological factors}

The results from the analysis of correlation between HIF-1a, GLUT-1, CA-9, and iNOS and clinicopathological variables are presented in Table 2 . With regard to the histological type and Lauren classification, GLUT-1 expression was higher in the intestinal type $(p=0.012)$; however iNOS expression was higher in the less-differentiated type and the diffuse type ( $p=$ $0.006, p=0.032$, respectively). HIF-1a and GLUT-1 expressions were significantly correlated with lymph node metastasis ( $p=0.009, p=0.008$, respectively). GLUT-1 and iNOS expressions were significantly correlated with the depth of invasion and advanced stage $(p=0.044, p=0.004 ; p=0.009, p=0.008$, respectively). However, statistically significant associations of CA-9 expression to a variety of clinicopathological variables were not identified.
Table 2. Relationship between hypoxia-related proteins and clinicopathological variables

\begin{tabular}{|c|c|c|c|c|c|}
\hline \multicolumn{6}{|c|}{ No. of expression(\%) } \\
\hline Variables & $\mathrm{n}$ & HIF-1 $\alpha$ & GLUT-1 & CA-9 & iNOS \\
\hline \multicolumn{6}{|l|}{ Age } \\
\hline$<60$ & 118 & $64(54.2)$ & $42(35.6)$ & $65(55.1)$ & $49(41.5)$ \\
\hline$\geq 60$ & 75 & $37(49.3)$ & $41(54.7)$ & $45(60.0)$ & $34(45.3)$ \\
\hline$p$ value & & 0.506 & $0.009^{*}$ & 0.501 & 0.602 \\
\hline \multicolumn{6}{|l|}{ Gender } \\
\hline male & 123 & $63(51.2)$ & $49(39.8)$ & $66(53.7)$ & $51(41.5)$ \\
\hline female & 70 & $38(54.3)$ & $34(48.6)$ & $44(62.9)$ & $32(45.7)$ \\
\hline p value & & 0.682 & 0.239 & 0.215 & 0.566 \\
\hline \multicolumn{6}{|l|}{ Histologic type } \\
\hline differentiated & 108 & $57(52.8)$ & $51(47.2)$ & $61(56.5)$ & $37(34.3)$ \\
\hline less-differentiated & 85 & $44(51.8)$ & $32(37.6)$ & $49(57.6)$ & $46(54.1)$ \\
\hline p value & & 0.889 & 0.182 & 0.871 & $0.006^{*}$ \\
\hline \multicolumn{6}{|c|}{ Lauren classification } \\
\hline intestinal & 130 & $71(54.6)$ & $64(49.2)$ & $71(54.6)$ & $49(37.7)$ \\
\hline diffuse & 63 & $30(47.6)$ & $19(30.2)$ & $39(61.9)$ & $34(54.0)$ \\
\hline p value & & 0.362 & $0.012^{*}$ & 0.337 & $0.032^{*}$ \\
\hline \multicolumn{6}{|l|}{ pT } \\
\hline $\mathrm{T} 1$ & 81 & $37(45.7)$ & $28(34.6)$ & $43(53.1)$ & $25(30.9)$ \\
\hline $\mathrm{T} 2-4$ & 112 & $64(57.1)$ & $55(49.1)$ & $67(59.8)$ & $58(51.8)$ \\
\hline p value & & 0.116 & $0.044^{*}$ & 0.351 & $0.004^{*}$ \\
\hline \multicolumn{6}{|l|}{$\mathrm{pN}$} \\
\hline N0 & 107 & $47(43.9)$ & $37(34.6)$ & $62(57.9)$ & $40(37.4)$ \\
\hline N1-3 & 86 & $54(62.8)$ & $46(53.5)$ & $48(55.8)$ & $43(50.0)$ \\
\hline p value & & $0.009^{*}$ & $0.008^{*}$ & 0.766 & 0.078 \\
\hline \multicolumn{6}{|l|}{ Stage } \\
\hline I & 91 & $41(45.1)$ & $30(33.0)$ & $51(56.0)$ & $29(31.9)$ \\
\hline II & 42 & $21(50.0)$ & $18(42.9)$ & $22(52.4)$ & $20(47.6)$ \\
\hline III & 60 & $39(65.0)$ & $35(58.3)$ & $37(61.7)$ & $34(56.7)$ \\
\hline$p$ value & & 0.053 & $0.009^{*}$ & 0.627 & $0.008^{*}$ \\
\hline
\end{tabular}
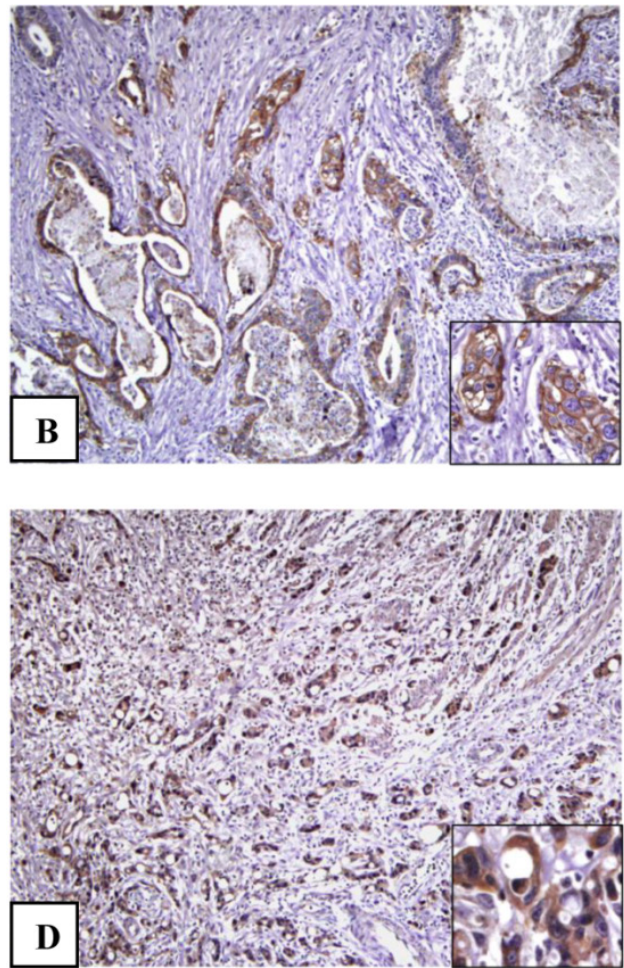

Fig I. The adenocarcinoma cells show positive immunohistochemical staining results for HIF-Ia (A), GLUT-I (B), CA-9 (C) and iNOS (D) $(x \mid 00)$. (A) Inset: HIF-Ia is localized in the nuclei of cancer cells (inset) (x400). (B) Inset: GLUT-I immunostaining shows positive reaction a strong membranous pattern in cancer cells $(\times 400)$. (C) Inset: CA-9 is strongly expressed in cell membrane of cancer cells (x400). (D) Inset: iNOS is expressed diffuse staining in the cytoplasm of cancer cells $(x 400)$. 


\section{Inter-relationship between HIF-I $\alpha$ and HIF-I $\alpha$-inducible proteins expression}

The results from the analysis of inter-relationships among HIF-1a, GLUT-1, CA-9, and iNOS expressions are presented in Table 3. Significant correlations were noted between HIF-1a and GLUT-1, CA-9, and iNOS. HIF-1a-positive cases showed significantly higher levels of GLUT-1, CA-9, and iNOS expression $(55.4 \%, 70.3 \%, 61.4 \%$, respectively) than those of HIF-1a-negative cases $(29.3 \% ; p=0.000$, $42.4 \% ; p=0.000,22.8 \% ; p=0.000$, respectively).

Table 3. Inter-relationship between HIF-I $\alpha$ and GLUT-I, CA-9, iNOS expression

\begin{tabular}{lllll}
\hline \multicolumn{5}{l}{ No. of cases(\%) } \\
\hline HIF-1a & No. of cases & GLUT-1 & CA-9 & iNOS \\
\hline positive & 101 & $56(55.4)$ & $71(70.3)$ & $62(61.4)$ \\
negative & 92 & $27(29.3)$ & $39(42.4)$ & $21(22.8)$ \\
p value & & $0.000^{*}$ & $0.000^{*}$ & $0.000^{*}$ \\
\hline
\end{tabular}

* statistically significant

\section{Survival analysis}

Survival analyses using the Kaplan-Meier method according to clinicopathological variables as well as all protein expression profiles are summarized in Table 4. The depth of tumor invasion $(p=0.002)$, presence of regional lymph node metastasis $(p=$ $0.000)$ and stage $(p=0.000)$ demonstrated a significant correlation with overall survival (OS). Out of 4 proteins analyzed, patients without GLUT-1 expression had longer OS compared to those with GLUT-1 expression (mean survival period, 40.2 months vs 37.5 months, respectively), which was statistically significant $(p=0.042)$. On the other hand, HIF-1a, CA-9, and iNOS expressions were not significantly related to patient prognosis. Multivariate analysis using the Cox proportional hazards model was performed to evaluate the independent prognostic predictors. As shown in Table 5, stage was the only independent prognostic marker $(p=0.000)$. However, GLUT-1 was not determined as an independent prognostic factor $(p=0.561)$.

\section{Discussion}

Tissue microarray (TMA) technology is an essential pathology research tool that has enabled simultaneous analysis of potential biomarker expression in a very large number of archived pathology specimens [19]. This technology allows us to save time, antibodies and costs associated with analyzing multiple specimens [19]. However, when the tumor is composed of heterogenous components and the observed molecular markers are heterogeneously expressed, tissue microarray (TMA) block implicates important shortcomings that it may not represent the full tissue section [20]. In this study, we determined the expression of HIF-1a and HIF-1a-inducible proteins, including GLUT-1, CA-9, and iNOS in GAs, using TMA technology and hoped to achieve a more precise understanding of the associations of these protein expressions with their clinicopathological characteristics and patient survival.

Table 4. Kaplan-Meier Survival analysis

\begin{tabular}{|c|c|c|c|c|}
\hline & & \multicolumn{3}{|c|}{ Gastric Adenocarcinoma $(n=193)$} \\
\hline & & No & $\begin{array}{l}\text { Mean time to sur- } \\
\text { vival } \\
\text { (months) }(95 \% \mathrm{CI})\end{array}$ & $\begin{array}{l}p \\
\text { value }\end{array}$ \\
\hline Age & $\begin{array}{l}<60 \\
\geq 60\end{array}$ & $\begin{array}{l}118 \\
75\end{array}$ & $\begin{array}{l}39.6(37.943-41.235) \\
37.2(34.799-39.581)\end{array}$ & 0.606 \\
\hline Gender & $\begin{array}{l}\text { male } \\
\text { female }\end{array}$ & $\begin{array}{l}123 \\
70\end{array}$ & $\begin{array}{l}38.8(36.995-40.648) \\
39.5(37.347-41.619)\end{array}$ & 0.612 \\
\hline $\begin{array}{l}\text { Differentia- } \\
\text { tion }\end{array}$ & $\begin{array}{l}\text { differentiated } \\
\text { less-differentia } \\
\text { ted }\end{array}$ & $\begin{array}{l}108 \\
85\end{array}$ & $\begin{array}{l}38.8(36.797-40.747) \\
39.4(37.457-41.335)\end{array}$ & 0.582 \\
\hline $\begin{array}{l}\text { Lauren clas- } \\
\text { sification }\end{array}$ & $\begin{array}{l}\text { intestinal } \\
\text { diffuse }\end{array}$ & $\begin{array}{l}130 \\
63\end{array}$ & $\begin{array}{l}39.3(37.584-40.980) \\
38.7(36.181-41.114)\end{array}$ & 0.714 \\
\hline pT & $\begin{array}{l}\mathrm{T} 1 \\
\mathrm{~T} 2-\mathrm{T} 4\end{array}$ & $\begin{array}{l}81 \\
112\end{array}$ & $\begin{array}{c}41.6(40.448-42.757) \\
37.2(35.007-39.394)\end{array}$ & $0.002^{*}$ \\
\hline $\mathrm{pN}$ & $\begin{array}{l}\text { N0 } \\
\text { N1-3 }\end{array}$ & $\begin{array}{l}107 \\
86\end{array}$ & $\begin{array}{l}42.2(41.419-42.957) \\
35.0(32.284-37.802)\end{array}$ & $0.000^{*}$ \\
\hline Stage & $\begin{array}{l}\text { I } \\
\text { II } \\
\text { III }\end{array}$ & $\begin{array}{l}91 \\
42 \\
60\end{array}$ & $\begin{array}{l}40.9(40.015-41.749) \\
41.8(40.145-43.529) \\
31.4(28.063-34.835)\end{array}$ & $0.000^{*}$ \\
\hline HIF-1 $1 \alpha$ & $\begin{array}{l}\text { negative } \\
\text { positive }\end{array}$ & $\begin{array}{l}92 \\
101\end{array}$ & $\begin{array}{l}40.3(38.614-41.911) \\
37.9(35.741-40.104)\end{array}$ & 0.283 \\
\hline GLUT-1 & $\begin{array}{l}\text { negative } \\
\text { positive }\end{array}$ & $\begin{array}{l}110 \\
83\end{array}$ & $\begin{array}{l}40.2(38.639-41.674) \\
37.5(35.005-40.016)\end{array}$ & $0.042^{*}$ \\
\hline CA-9 & $\begin{array}{l}\text { negative } \\
\text { positive }\end{array}$ & $\begin{array}{l}83 \\
110\end{array}$ & $\begin{array}{l}39.0(36.841-41.089) \\
39.1(37.201-40.905)\end{array}$ & 0.705 \\
\hline iNOS & $\begin{array}{l}\text { negative } \\
\text { positive }\end{array}$ & $\begin{array}{l}110 \\
83\end{array}$ & $\begin{array}{l}39.4(37.614-41.212) \\
38.6(36.360-40.772)\end{array}$ & 0.682 \\
\hline
\end{tabular}

* statistically significant

Table 5. Cox regression multivariate analysis

\begin{tabular}{llll}
\hline Variables & HR & $95 \%$ CI & $p$-value \\
\hline pT & 0.636 & $0.192-2.107$ & 0.459 \\
pN & 3.280 & $0.443-24.299$ & 0.245 \\
Stage & 5.806 & $2.807-12.001$ & $0.000^{*}$ \\
GLUT-1 expression & 1.262 & $0.577-2.758$ & 0.561 \\
\hline * statistically significant & & &
\end{tabular}

Urano et al [12] showed that HIF-1a was overexpressed in gastric cancer; but this expression showed no association with clinicopathological status and patient prognosis. Since then, a few studies have demonstrated that HIF-1a expression was associated with not only poor clinical features but also patient survival [11, 21]. In our study, we found that normal gastric tissues did not express HIF-1a, GLUT-1, and 
iNOS, although CA-9 was expressed in normal gastric mucosa, while HIF-1a, GLUT-1, and iNOS were overexpressed in GAs, which were all consistent with the findings of previous reports [12-15, 22]. We also found that HIF-1a expression was well correlated with the expression of GLUT-1, CA-9 and iNOS. Moreover, in accordance with earlier studies [11, 14, $15,22]$, we clearly demonstrated that the expression of HIF-1a and GLUT-1 were significantly correlated with lymph node metastasis, and the expression of GLUT-1 and iNOS were significantly correlated with advanced stage. Our data suggest that HIF-1a activation induces GLUT-1, CA-9, and iNOS [3,5], and that HIF-1a, GLUT-1, and iNOS may play an important role in promoting tumor development and dissemination. However, with regard to patient prognosis, only GLUT-1 was found to be correlated with patient prognosis by univariate analysis. The technical limitation of TMA may explain the lack of correlation of prognosis with markers other than GLUT-1.

GLUT-1, a member of the hypoxia-related protein family, is a basic high-affinity glucose transporter and is not detectable in a large proportion of cells from normal tissues, except in erythrocytes, the endothelial cells of brain, the perineurium of peripheral nerves, the germinal centers of reactive lymph nodes, renal tubules and placenta [18]. GLUT-1 is also predominantly upregulated in human malignancies since increased glucose uptake is one of the major metabolic changes observed in malignant tissues, and has been found to correlate with aggressive biologic behavior $[23,24]$. However, limited data are available regarding GLUT-1 expression in gastric cancer compared to studies on HIF-1a expression in gastric cancer. Noguchi et al [25] found an association between high GLUT-1 expression and poor post-operative survival in 70 gastric cancer patients. A more detailed study by Kawamura et al [14] revealed that $182(30 \%)$ cases of 617 gastric carcinomas were positive for GLUT-1 and found associations between GLUT-1 expression and tumor aggressiveness such as the depth of invasion, lymph node metastasis, stage, and patient survival. In our study, GLUT-1 expression was significantly associated with clinically aggressive tumor behavior, and therefore, GLUT-1 protein may be used as a prognostic factor in the context of GA. However, in multivariate analysis, GLUT-1 expression was not associated with patient survival. We believe that the short follow-up duration in our study may have affected the results of multivariate analysis, thus a further evaluation through an ongoing long-term study is required.

iNOS is the most active isoform of NO synthase. iNOS expression potentially serves as a global regulator of carcinogenesis and tumor behavior, because NO modulates some signal transduction pathways in cancer cells via posttranslational protein modifications [22]. Increased iNOS activity has also been observed in gastric cancer in common with other malignancies, and its expression was identified as a good marker for poor prognosis [15, 22]. Our results showed that iNOS expression was associated with stage, which is a significant poor prognostic marker, but was not associated with patient survival. However, further studies are warranted to examine its usefulness as a prognostic marker.

Finally, we cannot disregard the implication of hypoxia-related genes as a target for cancer therapy $[17,18]$. As remarked above, HIF-1a-inducible genes including HIF-1a are positive factors that promote tumor growth and survival. Tumor targeting therapy against specific biomarkers have the following advantages: (1) to deliver anti-cancer drugs to target specific tumor locations in the body; (2) to decrease the amount of drugs needed to attain a desirable therapeutic dose in target cancer cells; and (3) to reduce the amount of drugs in non-cancerous cells and to reduce the drug's side effects. Therefore, biomarker-targeted treatment that specifically blocks HIF-1a or GLUT-1 activity in gastric cancer expressing HIF-1a or GLUT-1 holds great promise for improving survival of patients with gastric cancer.

\section{Competing Interests}

The authors have declared that no competing interest exists.

\section{References}

1. Jemal A, Bray F, Center MM, Ferlay J, Ward E, Forman D. Global cancer statistics. CA Cancer J Clin. 2011; 61: 69-90.

2. Kim JG, Chung HY, Yu W. Recent advances in chemotherapy for advanced gastric cancer. World J Gastrointest Oncol. 2010; 2: 287-94.

3. Brahimi-Horn MC, Chiche J, Pouyssegur J. Hypoxia and cancer. J Mol Med (Berl). 2007; 85: 1301-7.

4. Griffiths EA, Pritchard SA, Welch IM, Price PM, West CM. Is the hypoxia-inducible factor pathway important in gastric cancer? Eur J Cancer. 2005; 41: 2792-805.

5. Maxwell PH, Pugh CW, Ratcliffe PJ. Activation of the HIF pathway in cancer. Curr Opin Genet Dev. 2001; 11: 293-9.

6. Eckert AW, Kappler M, Schubert J, Taubert H. Correlation of expression of hypoxia-related proteins with prognosis in oral squamous cell carcinoma patients. Oral Maxillofac Surg. 2012; 16: 189-96.

7. Kim JA, Kim SJ, Do IG, et al. Hypoxia-associated protein expression in primary central nervous system diffuse large B-cell lymphoma: does it predict prognosis? Leuk Lymphoma. 2011; 52: 205-13.

8. Kwon HC, Kim SH, Oh SY, et al. Clinicopathological significance of p53, hypoxia-inducible factor 1alpha, and vascular endothelial growth factor expression in colorectal cancer. Anticancer Res. 2010; 30: 4163-8.

9. Ogane N, Yasuda M, Shimizu M, et al. Clinicopathological implications of expressions of hypoxia-related molecules in esophageal superficial squamous cell carcinoma. Ann Diagn Pathol. 2010; 14: 23-9.

10. Sun HC, Qiu ZJ, Liu J, et al. Expression of hypoxia-inducible factor-1 alpha and associated proteins in pancreatic ductal adenocarcinoma and their impact on prognosis. Int J Oncol. 2007; 30: 1359-67.

11. Qiu MZ, Han B, Luo HY, et al. Expressions of hypoxia-inducible factor-1alpha and hexokinase-II in gastric adenocarcinoma: the impact on prognosis and correlation to clinicopathologic features. Tumour Biol. 2011; 32: 159-66.

12. Urano N, Fujiwara Y, Doki $Y$, et al. Overexpression of hypoxia-inducible factor-1 alpha in gastric adenocarcinoma. Gastric Cancer. 2006; 9: 44-9. 
13. Griffiths EA, Pritchard SA, Valentine HR, et al. Hypoxia-inducible factor-1alpha expression in the gastric carcinogenesis sequence and its prognostic role in gastric and gastro-oesophageal adenocarcinomas. Br J Cancer. 2007; 96: 95-103.

14. Kawamura T, Kusakabe T, Sugino T, et al. Expression of glucose transporter-1 in human gastric carcinoma: association with tumor aggressiveness, metastasis, and patient survival. Cancer. 2001; 92: 634-41.

15. $\mathrm{Li} \mathrm{LG}, \mathrm{Xu} \mathrm{HM}$. Inducible nitric oxide synthase, nitrotyrosine and apoptosis in gastric adenocarcinomas and their correlation with a poor survival. World J Gastroenterol. 2005; 11: 2539-44.

16. Driessen A, Landuyt W, Pastorekova S, et al. Expression of carbonic anhydrase IX (CA IX), a hypoxia-related protein, rather than vascular-endothelial growth factor (VEGF), a pro-angiogenic factor, correlates with an extremely poor prognosis in esophageal and gastric adenocarcinomas. Ann Surg. 2006; 243: 334-40.

17. Semenza GL. Targeting HIF-1 for cancer therapy. Nat Rev Cancer. 2003; 3: 721-32.

18. Luo XM, Zhou SH, Fan J. Glucose transporter-1 as a new therapeutic target in laryngeal carcinoma. J Int Med Res. 2010; 38: 1885-92.

19. Chen W, Foran DJ. Advances in cancer tissue microarray technology: Towards improved understanding and diagnostics. Anal Chim Acta. 2006; 564: 74-81.

20. Boone J, van Hillegersberg R, van Diest PJ, Offerhaus GJ, Rinkes IH, Kate FJ. Validation of tissue microarray technology in squamous cell carcinoma of the esophagus. Virchows Arch. 2008; 452: 507-14.

21. Mizokami K, Kakeji Y, Oda S, et al. Clinicopathologic significance of hypoxia-inducible factor 1alpha overexpression in gastric carcinomas. J Surg Oncol. 2006; 94: 149-54.

22. Zhang $\mathrm{W}, \mathrm{He} X \mathrm{X}, \mathrm{Ma} \mathrm{YY}$, et al. Inducible nitric oxide synthase expression correlates with angiogenesis, lymphangiogenesis, and poor prognosis in gastric cancer patients. Hum Pathol. 2011; 42: 1275-82.

23. Younes M, Juarez D, Lechago LV, Lerner SP. Glut 1 expression in transitional cell carcinoma of the urinary bladder is associated with poor patient survival. Anticancer Res. 2001; 21: 575-8.

24. Kunkel M, Reichert TE, Benz P, et al. Overexpression of Glut-1 and increased glucose metabolism in tumors are associated with a poor prognosis in patients with oral squamous cell carcinoma. Cancer. 2003; 97: 1015-24.

25. Noguchi Y, Marat D, Saito A, et al. Expression of facilitative glucose transporters in gastric tumors. Hepatogastroenterology. 1999; 46: 2683-9. 